\title{
Adolfo Couve, Cuando pienso en mi falta de cabeza (La segunda comedia): "Una mediocre réplica de lo auténtico"
}

Adolfo Couve, When I think of M y Lack of a Brain (The Second Comedy):

"A M ediocre Reply to the Authentic"

M arcia M artínez Carvajal

Universidad de Concepción. Concepción, Chile

E-mail: marcmart@udec.cl

\section{CUAND 0 PIENSO EN LA PERDIDA}

E L AÑ O 1995 Adolfo Couve publica La comedia del arte, novela donde ac- ciones y hechos cotidianos setornan en tragedia y constituyen la semblanza de un personaje atrapado por su condición aislada (Camondo), en un lugar periférico que ha tomado por única tierra ( $C$ artagena), marginal en una socie dad que tiende a rechazarlo, donde el artista es el reproductor más prescindible del grupo, careciendo además de los medios óptimos para crear, fracasando finalmente en su empresa. Por lo anterior, C amondo deja de crear (y de creer), abjura de sus talentos, pierde su modelo y, finalmente, pierde su cabeza.

Como réplica ineludible, Couve escribe Cuando pienso en mi falta de cabeza (2000) que lleva por subtítulo La segunda comedia ${ }^{1}$, obra inédita al minuto en que el autor se quita la vida en 1998 y que, si bien se puede ver como una segunda parte, arranca desde ella para revisitar el tema de la reflexión sobre el arte a través de los personajes de su primera comedia, en una segunda que hace delirar el método, el lenguaje y las estructuras. Así lo expone Claudia D onoso en el prólogo a La comedia del arte:

\footnotetext{
${ }^{1}$ La obra, al igual que La comedia del arte, está dispuesta en tres capítul os que, en este caso, se aleja de la correspondencia aristotélica de presentación, desarrollo y desenlace, cuestión formal que nos presenta la dificultad que tiene la obra de aferrarse al paradigma clásico.
} 
Couve aborda en sus escritos un problema estético donde entre otras cosas se evocan particulares ecos de un mestizaje cultural cuyos movimientos se registran sobre todo en el lenguaje (C ouve, 1995:13).

Adolfo Couve ha sido calificado por la crítica como un personaje excéntrico, en cuanto a su trabajo plástico-literario ${ }^{3}$ y su autoexilio en Cartagena ${ }^{4}$, apareciendo en la narrativa chilena como extemporáneo, inclasificable en generación o vanguardia alguna, además de su insistente búsqueda de la belleza, su visión del trabajo del arte por el $a^{2} e^{5}$ y la verdad que en ella reside, cuestiones que lo diferencian del arte contingente, político o experimental de sus contemporáneos.

Parto leyendo en Cuando pienso en mi falta de cabeza la constatación del fracaso de la empresa artística y personal, el derrumbe del que nos habla Francis Scott Fitzgerald (1991), en cuanto a la misión del arte que pretende CouveCamondo, llegando a trizar el paradigma de la belleza y cotejar la inutilidad del oficio, que si bien ha fracasado, aun roto sigue guardándose y ejerciéndose. En su relación intensa con el arte, Couve se evade y deja de pertenecer al círculo artístico central, no acepta preguntas ni vida social en sus clases universitarias, se recluye en Cartagena para llegar a ser un "escritor de verdad", escribiendo no para complacer editoriales sino para completarse, para sobrellevar su tragedia personal ${ }^{6}$.

La elección deC artagena como lugar y punto de partida para sus historias es una elección sin explicación ni fundamento, impetuosa, tal como lo menciona Couve en la entrevista concedida a C ristián Warnken:

${ }^{2}$ Cuando me refiero a "la crítica” pienso en los artículos escritos por Luis Cécereu, Patricia Espinoza, José Alberto dela Fuente, M arcelo Simonetti el gnacio Valente, cuya revisión permitió trazar la idea que la crítica tiene de Adolfo Couve y su obra.

3 Su pintura corresponde a lo que él mismo definió como "un realismo nostálgico". Se caracterizó por visiones intimistas de pequeños retratos, paisajes, bodegones muy simples, figuras en interiores y al aire libre, además de objetos de su vida cotidiana. El mismo Couve aclara que el pintor realista no copia la realidad, sino que la traduce con una actitud mística, absolutamente consciente de la muerte y con una necesidad de aferrarse a lo que ve (Warnken, La belleza del pensar).

${ }^{4}$ Sobre esto, Justo Pastor M ellado señala: "La situación de extrañamiento que significa practicar esta pintura a contracorriente, excluida de las tendenciasmayoritarias". "Sobre Couve", Justo Pastor M ellado.

${ }^{5}$ El arte por el arte es su consigna, según lo que manifiesta en la entrevista ya mencionada concedida a Cristián Warnken.

${ }^{6}$ En este ambiente de relación con lo clásico, magnánimo y sublime, se presenta una tensión entre lo global y lo local, manifestada en el esfuerzo por resucitar la provincia como lugar, territorio y posesión del artista, rehuyendo la metrópoli y lo que está establecido, paradigmas estéticos y sociales. 
No sé por qué me fui a Cartagena, me fui el año 83. M e quería ir de Chile. Pero me fui de $C$ hile en realidad, porque yo encuentro a $C$ artagena distinto a C hile. Como no había plata ahí, no lo habían destruido todo, no habían convertido las cosas en otras cosas (... ) yo tengo un camino de tierra fuera de mi casay hay vacas esperando; cuando voy a hacer clases a Santiago me encuentro dosvacas sentadas. C artagena es un lugar marginal de verdad. M uchos escritores hablan de la marginalidad, pero yo vivo la marginalidad (Warnken, "Los grandes artistas viven la eternidad aquí", de La belleza del pensar).

C artagena es lugar y también tema desde su decadencia y olvido, la lectura y el proceso de estetización que realiza Couve encontrará en ella el lugar de la belleza, y es éste el proceso anómalo que rige la escritura de estos últimos dos libros, donde el gran panorama social y burgués del que se hace cargo el estilo realista no es sino una mediocre réplica de aquello que al guna vez fue. A partir de lo anterior, existiendo una ruptura temática con el realismo, es interesante la propuesta de Couve en cuanto a su insistencia en la escritura de tintes real istas, narración impersonal detrás de la cual, según su visión, no hay nadie, donde se acaba el yo. En La comedia del arte está presente dicho narrador omnisciente, pero ya fracturado, ya que está consciente de su trabajo y sus dos fracasos anteriores en el intento de escritura de esta comedia, interviniendo con calificaciones y exclamaciones personales las peripecias de C amondo, dejando así su altar omnisciente y objetivo, para dolerse de su personaje y su historia, intuyéndose aquí el trabajo de dobles Camondo-Couve.

En la primera y última parte de Cuando pienso en mi falta de cabeza es el propio $\mathrm{C}$ amondo quien relata el viaje en busca de su cabeza perdida, presentándose el narrador omnisciente en el 'Cuarteto menor' que, en formato breve y a modo de pequeñas secuencias de acción o fotografías, nos presenta variaciones sobre el tema de perder la cabeza, formato que muestra la incapacidad de la narración de estructura tradicional y la dificultad del proyecto realista de C ouve, reafirmando su fractura iniciada en la escritura de La comedia del arte.

Frente al problema del narrador y el desplazamiento de la pintura a la literatura, cuestión presente en Couve tanto en la organización del discurso como en la presentación de las imágenes que rodean sus narraciones, calificadas por la crítica como 'cuadros plásticos', 'retrato de época', etc., los medios descriptivos de personajes y ambientes trascienden el estilo, se hacen pintura para luego hacerse comedia, parodia. Acerca de esto, Justo Pastor M ellado señala:

En su caso la narración literaria no acarrea el abandono de la pintura sino más bien la picturalización de la escritura. C ouve escribe como pinta, fragmentariamente, temblorosamente, esencialmente: como esencial es la economía del gesto y del color. Couve escribe, en fin, porque reconoce la insatisfacción dela 
pintura frente a la omnipresencia del narrador total que pasea su ojo por todo el universo (M ellado, "Sobre Couve").

Así, Cuando pienso en mi falta de cabeza es vista como el apogeo de la parodia, de la burla de Couve contra el sistema (pictórico-literario) y contra sí mismo, presentándose como una novela contra el centro (sin cabeza), por la provincia (periferia, la provincia que es el exilio, el abandono de los otros y de sí mismo), desde la hipérbole del espectáculo, en altares, fiestas y ritos corrientes: "la tragedia de lo cotidiano", como anuncia D onoso en el prólogo citado, y el purgatorio donde vivía Couve "una mediocre réplica de lo auténtico", cómo él mismo dice (Couve, 2000: 92).

\section{ERRANTE Y DESCABEZAD 0}

Couve porta en sí la tradición artística occidental, un ideal clásico de la belleza y del don, de la acción sublime de crear. Al ser abandonado por los dioses, abjurando de su condición de creador, Camondo sucumbe. Así, la vida y función quelefuedada por las divinidades, en tanto quecreación artística, está rota como espejo en mil pedazos, trastocada, carente de sentido, y Camondo emprende su salida así como la aventura caballeresca del Q uijote, sin ruta: la realidad de la que él debía hacerse cargo ha desaparecido.

La presentación de sus relatos muestra un paisaje descrito intensamente, como una pintura inicial, como la primera en la exposición que anuncia el color de la muestra. Como antes señalé, Couve, desde su trabajo al margen, encierra en sí la figura de la indefinición disciplinaria. Pintura y literatura se cruzan y traspasan. Si bien Couve deja de pintar para escribir, y luego deja de escribir para volver al arte, residen en él ambos oficios y se confunden. En su opción del "artepor el arte", C ouve se empeña en su verdadero eintenso trabajo deartista, creador. $\mathrm{M}$ as, en la debilitación del orden, del sentido y del arte diluyéndose en lo cotidiano, ya no es posible el ideal clásico de belleza, su creación y el lugar de la belleza no es sino en la periferia, en la marginalidad, en la caída.

En Cuando pienso en mi falta de cabeza, el narrador protagonista, Camondo, nos presenta el relato a través de una prosa ya no preocupada de la naturaleza 0 de problemas políticos o sociales, sino ocupada de la reflexión sobre el arte desde la propia historia del decapitado errante, reflexión esta vez fragmentada en cuanto a la narración, a diferencia de L a comedia del arte, donde un narrador omnisciente daba cuenta de la historia de Camondo, Marieta, Aosta y de Cartagena, desdeun decir teñido de la emoción del acto y conmiseración por la 
historia de su criatura, consciente de la imposibilidad de su empresa, pero guardando aún el orden y la necesidad de terminar la historia, de llevarla a un fin.

La historia de La comedia del arte termina con el "categórico despojo" de la cabeza de Camondo. Convertida esta amputación en acto de sublimación esté tica e iniciático, pasa a ser pretexto de la segunda narración, que es constatación de la fractura de los objetos, las estructuras, de la razón. Es también el procedimiento a través del cual se hace patente la conciencia de la caída de su autor, la justificación del fracaso, que provoca una búsqueda que no es sino el desplazamiento inútil de un cuerpo acéfalo, adoptando a su vez cabezas ajenas, máscaras que son imágenes comunes, corrientes. Al no existir cabeza no existe vista, oído ni sabor, el narrador cuenta desde su memoria, reconstruye el paisaje desde sus recuerdos, añora su cabeza pensando con la escritura precedente: desde lo ya dicho en La comedia del arte. El artista (Camondo-C ouve) ya no es sino muchedumbre. $Y$ el entorno se encarga, a través de la hipérbole de la imagen de la cabeza (la playa de Cartagena en verano), en demostrar la ausencia. En una primera instancia, la cabeza se suple con un disfraz (religioso), dejando, en lugar de cabeza, vacío y sombras:

Para mí fue la solución, el disfraz, la única forma de completar mi figura, ya que una vez dentro de esas ropas eché hacia delante el holgado capuchón y suplí, con las sombras que éste encerraba, la cabeza, los rasgos, las facciones, mis ojos, la boca, el mentón, la frente (C ouve, 2000: 38).

Ya recuperada una cabeza sustituta, C amondo asiste a la "fiesta de la calle Pedro M ontt", ante la cual debe presentarse disfrazado, haciendo elección de una máscara con un rostro de un señor cualquiera. Esta fiesta constituye el último esfuerzo de Camondo de insertarse en la vida, con un rostro común, portando el rostro de todos-nadie.

\section{CUARTETO MENOR, UNA PAUSA}

Este fragmento está compuesto de las historias de los otros, los perjudicados a partir de la historia de Camondo, quienes abren la narración. Como antes mencioné, los relatos son fotografías de sus acciones, breves instantáneas de momentos en queellos encuentran "el sentido" al perder la cabeza. Se presenta la historia de la esposa deB ombillín, deSandro, de la hija del célebre pintor $M$ oya, y de la musa, M arieta, que le hace tanta falta a Camondo como su cabeza. Esta última historia está marcada por una acción: la de abandonar objetos esperando 
la reacción de los otros, los transeúntes, cercano al procedimiento plástico de la instalación, hasta que se abandona a sí misma, desnuda. La incomprensión de su acto, lo que dicen los otros de ella desde el lenguaje coloquial, confirma lo que para los otros es locura, pero que para ella, desde la actitud compasiva de su narrador, es la búsqueda de pertenecer. Se perfila así la última acción de arte de la model $0^{7}$.

En Gastón Aosta, "el fotógrafo playero", está más clara una de las ideas que cruza este cuarteto y la historia de Camondo en general, el redescubrimiento de la belleza, alejada de la escuela clásica. El descubre la esencia del arte a través de un procedimiento banal: rescatar un chancho que había caído a un pozo.

La pérdida de cabeza por pasiones queminan la razón y queluego son reproducidas en literatura se presenta, por ejemplo, en la figura de la soltera consagrada al cuidado de su madre, cuyo anhelo es viajar a Europa, cuna de sus mayores placeres (arte y literatura, lo que siem pre vio por reproducciones enciclopé dicas), y termina cediendo ante el amor, sojuzgada a su cuerpo, a lo bajo, a su pasión por un payaso ${ }^{8}$. Luego metaforiza su romance con elevadas palabras y versos fastuosos, último intento de la solterona por aferrarse al arte.

Los cuadros de este cuarteto terminan con la escena del espejo robado a M arieta que sólo puede reflejar la pieza de su antigua dueña, lo que trastorna a su actual poseedor, quien siente que perdió su rostro y su posición en la vida?; y la escena del robo y devolución de la pintura que le daba sentido a la vida de la hija del "célebre pintor M oya", la queluego es envuel ta como una recién nacida en pañales, para ser devuelta a su lugar en el museo ${ }^{10}$. U Itima imagen: el banquetegrotesco del chancho rescatado, el chancho cuyo rescate develó una nueva forma de ver. Todos los narradores-personajes sienten y exclaman "iqué manera la mía de perder la cabeza!": todos son Camondo. Todos pierden y a partir de esto se trastoca su vida, se adopta un nuevo sentido, paródico, sin sentido.

${ }^{7}$ En La comedia del arte, M arieta traiciona a Camondo con Aosta, el fotógrafo. En los códigos de la historia M arieta sería el arte, en decadencia pero llena de la sutil belleza de su pasado, ella es el arte que se entrega gustosa a las nuevas ten dencias para luego quedar vacía y dejar vacío a quien vivió de ella.

8 “Bombillín, esa máscara de colores estridentes, la miró serio, como si Raúl Ramírez se asomara tras el hombre de fantasía" (Cuando pienso en mi falta de cabeza, Couve, 2000: 64).

9 "El espejo reprodujo el rostro consternado de una mujer que por primera vez tuvo noción de lo frágil que resultaba ser el jefe de hogar, su sostén, el pater familias, el guía de sus hijos, ese empleado de hoja de servicio impecable, juicioso, que para todo tenía una respuesta acertada" (C ouve, 2000: 70).

10 "Acción de arte" que recuerda hechos de la contingencia nacional reciente. 


\section{POR EL CAMINO, EN TRANSITO}

Camondo sigue su camino y narra su encuentro con el coleccionador de mue bles, Albrecht (figura intrigante que nos dice que en los muebles está la tradición, son ellos los que portan una clase olvidada), y la noticia sobre su cabeza, encontrada en una botillería, envuelta también en pañales, vendida a la iglesia, reformada y ocupada en la imagen de un santo que esconde una reliquia. Esta es ahora la utilidad de su cabeza, que puede ser como la de tantos otros decapitados de la historia: representar, ser alegoría exigua. Así, la cabeza de Camondo pasó a ocupar otro cuadro plástico, otra representación:

O s dieron su nombre, os lo han prestado, como cuando el actor mejor, escéptico y vicioso, maquillado, setransforma einterpreta un papel modelo (Couve. 2000: 92).

El mártir representado es San Tarcisio ${ }^{11}$, quien muere al llevar a Jesús (la comunión) al circo ${ }^{12}$, siendo interceptado por unos músicos que volvían de una fiesta, los que, al ver que Tarcisio atesoraba algo con gran celo, tratan de quitársel o dándole muerte. Todo esto presenciado por su amigo $\mathrm{M}$ arcos $\mathrm{C}$ rassus, quien no hace nada para defenderlo. Así, podemos decir que es Tarcisio doble de Camondo, al pagar con la muerte la pasión y en el sacrificio.

Camondo en su peregrinar asiste a diversas representaciones, una de ellas la del "Fausto de Gounod", donde se encuentra atrapado por Albrecht, quien no lo deja huir. Esta representación es criolla y de baja factura, popular. Asimismo, asiste también a la representación de su rol (su cabeza) de santo, ante la cual pierde el sosiego. Es esta seguidilla de representaciones la que va mostrando a Camondo lo artificioso de su camino, lo paródico de su intento:

Camondo, al proscenio, yo al último rincón del paraíso; ese teatrucho destartalado del Colón de San Pablo con M atucana, donde obtuviste la mención honrosa en el concurso de pintura al aire libre; habían alzado la mortaja del telón... (Couve, 2000: 47).

Entonces me volví y enfrenté a los fieles que, recogidos muchos de ellos, creían aquello un cadáver incorrupto, un milagro.

- ¡Ese soy yo, soy yo! -grité a voz en cuello.

(...)

${ }^{11}$ Tarcisio significa: "Valeroso" (Tarsus = valor).

${ }^{12}$ Esto según C ouve, no a la cárcel como en la historia original. 
-Esa es mi cabeza -le dije-, ése soy yo -el cura asintiendo pensó que al llevarme el amén, el escándalo no pasaría a mayores. Me despidió frente a la plaza (C ouve, 2000: 85)

M ás adelante, su vida junto a Filomena, en la miseria de los extramuros dela ciudad, es, según después descubre, una convivencia con la muerte, donde pre sencia el simulacro de la sanación, con el cementerio de fondo, junto a una serpiente de mascota. Asimismo, es Filomena quien anuncia desde su miserable imagen la imposibilidad de futuro (la narración que no termina sino en el camino, en tránsito, en reversa), y es ella quien lo viste con el traje de un muerto:

Un día me explicó que sólo tenía ojos para ver el pasado, y que mientras comíamos se entusiasmaba con evocar un verdadero corso de fantasmas (C ouve, 2000: 94).

Es en otra representación donde C amondo vuelve a encontrar la belleza en lo simple (un ángel del pesebre), que lo vuelve a tentar con el arte, en medio de signos de muerte, para asistir luego a otra simulación, la del palacete en que se supone viven los adinerados del pueblo y el ángel que tentó a Camondo, queno es sino una fachada de utilería. Es una mera apariencia hasta su paso por el averno, un averno que es el simulacro de sí mismo, un infierno de utilería confeccionado con palos de fósforo y papel mantequilla.

¡O h réplicas de un destino, de una pena, de la decisión heroica de haber dejado atrás arte y belleza! $Q$ ué soy sino un sobreviviente de un castigo a medias, incompleto: la cera, artimaña fallida de un cielo vencido, Apolo, Zeus, las tantas musas, un Caronte impago, ya sin voluntad para mover los remos y completar la barca con sombras sin vuelta (C ouve, 2000: 100).

El último capítulo de este tránsito, el baile de sombras, es una pasarela de personajes, en medio de signos de opulencia y fuego, juntando la supuesta alcurnia con lo popular provinciano, mezclándose lo que se supone alta cultura (identificado con el dinero y el poder adquisitivo) y cultura popular (simple, en decadencia). H eaquí que la llegada del cónsul revive (o mata por fin) a C amondo, es aquél quien lo valida, le pide leer el arte presente en el palacete de las apariencias, para pasar a una cena al "estilo de un rey con su pintor favorito". Se produce por fin la partida, por el camino deSantiago, con todo el tiempo del mundo, con la eternidad sin sentido, sin cabeza, en la apariencia. Se presenta así el libro en tránsito, no resuelto, a la espera de su cabeza, de su fin. 


\section{DESDE LA PERIFERIA ACEFALA A IMITAR EL GESTO DE MENARD}

D on Q uijote esboza lo negativo del mundo renacentista; la escritura ha dejado de ser la prosa del mundo, las semejanzas y los signos han roto su viejo compromiso; las similitudes engañan, llevan a la visión y al delirio; las cosas permanecen obstinadamente en su identidad irónica: no son más quelo que son; las palabras vagan a la aventura, sin contenido, sin semejanza que las llene; ya no marcan las cosas; duermen entre las hojas de los libros en medio del polvo (Foucault, 1968: 54).

Couve, excéntrico desde su exilio y desde su pintura/literatura ageneracional, persiste en la no pertenencia desarrollando su proyecto: escribir la novela realista francesa del siglo XIX, la prosa de Flaubert. Así, imitando el gesto de Pierre $M$ enard ${ }^{13}$, Couve intenta escribir "la novela realista". En este plan, al llegar a Camondo y La comedia del arte, con la reflexión sobre el arte y la constatación de la imposibilidad de la misma, su proyecto se dificulta, el fracaso es relativo, más bien se tranfforma. No se busca la gran conclusión en el problema, sino la sinuosidad del lenguaje, de las imágenes, el sentido perdido, hacia el sentido imposible, la escritura de Cuando pienso en mi fal ta de cabeza. Así como C ouve imita el gesto de $M$ enard, Camondo el del $Q$ uijote, partiendo de la idea de que Camondo está hecho de la tradición de las artes plásticas que residen en Couve. Es él la encarnación de lo que ya no puede ser el arte, ante la crisis de la representación realista es forzado a abjurar al ser superado por la fotografía, por los payasos.

A partir de Foucault cuando nos dice "la escritura y las cosas ya no se asemejan. Entre ellas, D on Q uijotevaga a la aventura" (Foucault, 1968: 55), también Camondo y su arte real ista que ya no puede reflejar, pierde la cabeza y vaga a la aventura de su búsqueda y recuperación errónea, simple, común, desacralización de la figura del artista. Lo anterior se ve tanto en Couve con la historia de su doble Camondo, como en la dela viuda y su romance con el payaso en su diario de vida, como Sandro y su historia pictórica, como Aosta descubriendo la verdad de la belleza en el rescate de un chancho.

Couve, como dice Foucault, a través de su doble Camondo está todo hecho de lenguaje:

13 “N o quería componer otro Q uijote - lo cual es fácil- sino el Q uijote. Inútil agregar que no encaró nunca una trascripción mecánica del original; no se proponía copiarlo. Su admirable ambición era producir unas páginas que coincidieran - palabra por palabra y línea por líneacon las de M iguel de Cervantes" (Borges, 1998: 47). 
Todo su ser no es otra cosa que lenguaje, texto, hojas impresas, historia ya transcrita. Está hecho de pal abras entrecruzadas; pertenece al la escritura errante por el mundo entre la semejanza de las cosas (Foucault, 1968: 53).

A partir de lo anterior, Couve, desde la pintura transfigurada en literatura, escribe el mundo para comprobar el arte, desplazamientos necesarios para seguir en su esfuerzo por el arte. ¿Cuál es el molde que se quiere romper, a fuerza de repeticiones? H al Foster nos dice: "U navez más el desarrollo de estos acontecimientos no es lineal ni sus rupturas limpias" (Foster, 2001: 213). Si el estilo realista ha dejado su condición de tiempo o movimiento histórico, CamondoCouve son a la vez renacentistas y decadentes en el siglo XX:

Yo estuve en Florencia cuando la redondez de la tierra se impuso y la línea del horizonte cayó por los suelos, todo se volvió profundidad, conocimos la distancia, la atmósfera permitió el volumen y la luz tomó contacto real por primera vez con las cosas, mostrándonos en su roce la esencia de las mismas (Couve, 2000: 41).

No hay esquema claro que seguir resistiendo, por lo que estas pérdidas y disoluciones no son sino pequeñas explosiones, que muestran que es inverosímil la mimesis y que esto se convierte en espectáculo, en fachada de utilería.

\section{BIBLIOGRAFIA}

Borges, Jorge Luis. 1998. Ficciones. M adrid: Alianza Editorial.

Cécereu, Luis. 1991. "A propósito de C ouve y H agel, narradores", en Aisthesis N 024. pp. 79-102.

Couve, Adolfo. 1995. La comedia del arte. Prólogo por Claudia D onoso. Santiago, Chile: Editorial Planeta.

Couve, Adolfo. 2000. Cuando pienso en mi falta decabeza (la segunda comedia). Prólogo por Adriana Valdés. Santiago, Chile: Editorial Seix Barral.

De la Fuente, José Alberto. 2001. "Identidad y realismo en la narrativa de Adolfo Couve", en Literatura y Lingüística $N$ ㅇ 13, pp. 89-104.

Espinoza, Patricia. 2000. "Inquietante novela póstuma", en El M etropolitano, 19 de marzo. El URL del documento es http://www.letras.55.com/couve221103.htm

Fitzgerald, Francis Scott. 1991. El Crack up. Barcelona: Editorial Anagrama.

Foster, $\mathrm{H}$ al. 2001. El retorno de lo real. La vanguardia a finales de sigl o. M adrid: Ediciones Akal.

Foucault, M ichel. 1968. Las palabras y las cosas. M éxico: Siglo XXI.

Lira, Sonia y M iranda, Rodrigo. 2003. "Al rescate de Adolfo C ouve", en Revista Q ué Pasa, agosto. EI URL del documento es http://letras.s5.com.istemp.com/ couve2212.htm 
M ellado, Justo Pastor. "Sobre Couve". El URL del documento es http://www. justopastormellado.cl/escritos_cont/semanal/2002/08_agosto_2002/ 20020820.html

Simonetti, M arcelo. 2002. "La vuelta del aristócrata", en Revista del Sábado, septiembre. EI U RL del documento es http://letras.55.com.istemp.com/couve200103.htm

Valente, I gnacio. 1998. "Adolfo C ouve, ilustre solitario", en El M ercurio, 21 de marzo. EI U RL del documento es http://letras.55.com.istemp.com/couve023.htm

Warnken, C ristián. "Los grandes artistas viven la eternidad aquí, extracto editado de la entrevista a Adolfo C ouve realizada en el programa de televisión La belleza del pensar. EI URL del documento es http://letras.s5.com.istemp.com/couve 2908021.htm 